\section{Abrikossoff's Tumor (Granular Cell Tumor) of the Breast: A Case Report and Literature Review}

\section{Abstract}

Abrikossoff's tumors can become a difficult diagnostic challenge for the physicians because of their clinical, mammographical, and sonographical aspects, mimicking a primary breast carcinoma.

We report of a healthy 31-year-old Bulgarian woman who presented to us for an assessment of a firm and thick palpable mass in the inferior medial quadrant of the left breast several months after giving birth. The ultrasonography (US) revealed a hypoechoic, nonhomogeneous solid mass $(21 / 17 \mathrm{~mm})$ with axillary lymphadenopathy. Wide local excision of the lesion was done. The final histologic evaluation confirmed the diagnose - benign granular cell tumor (GCT) of the breast with non-tumoral margins. At the one year follow up there was no evidence of a recurrent lesion. GCT is one of the rarest tumors of the breast. Correct recognition of granular cell tumor is crucial for an adequate therapeutical approach.

Keywords: Abrikossoff's tumor; Breast; Granular cell tumor

Received: November 24, 2017; Accepted: December 08, 2017; Published: December 15, 2017

\section{Introduction}

Granular cell myoblastoma was originally described by Alexei Abrikossoff in 1926, assuming a myogenic origin [1]. Today it is considered that these type of neoplasms originate from putative Schwann cells based on their immunophenotypic and ultrastructural characteristics [2]. Granular cell tumors (GCT) are usually benign but less than $2 \%$ of them show the tendency to become a malignant version, associated with a poor prognosis [3].

When located in the breast, Abrikossoff's tumors can become a serious diagnostic challenge for the physicians because of their clinical, mammographical, and sonographical aspects, mimicking a primary breast carcinoma [4]. The histopathological and immunohistochemical result gives the definitive diagnose. The treatment of GCT should be wide local excision with clear margins of healthy breast tissue [5].

\section{Case Presentation}

We report of a healthy 31-year-old Bulgarian woman who presented to us for an assessment of a firm and thick palpable mass in the inferior medial quadrant of the left breast several months after giving birth.

\section{Sedloev $\mathrm{T}^{1^{*}}$, Terziev $\mathrm{I}^{2}$, Usheva S ${ }^{1}$, Pirdopska T², Spirdonov $\mathrm{J}^{3}$, Spiridonova $\mathrm{T}^{1}$, Jelev $\mathbf{G}^{1}$ and Korukov $\mathbf{B}^{1}$}

1 Department of Surgery, University Hospital "Tzaritza Joanna - ISUL", Medical University of Sofia, Sofia, Bulgaria

2 Department of Pathology, University Hospital "Tzaritza Joanna - ISUL", Medical University of Sofia, Sofia, Bulgaria

3 Department of Medical Imaging, University Hospital "Tzaritza Joanna ISUL", Medical University of Sofia, Sofia, Bulgaria

*Corresponding author: Theophil Sedloev

Department of Surgery, University Hospital "Tzaritza Joanna - ISUL", Medical University of Sofia, Bulgaria Sofia 1527, Bulgaria.

झ theosed@abv.bg

Tel: +359888624327

Fax: 9432144

Citation: Sedloev T, Terziev I, Usheva S, Pirdopska T, Spirdonov J, et al. (2017) Abrikossoff's Tumor (Granular Cell Tumor) of the Breast: A Case Report and Literature Review. J Rare Disord Diagn Ther Vol. 3 No. $6: 17$

Physical examination verified a lesion about $2 \mathrm{~cm}$ in diameter, relatively mobile from the chest wall, painful during palpation, with enlarged lymph nodes in the left axilla. There were no pathological findings in the right breast or axillary and supraclavicular lymphadenopathy.

The ultrasonography (US) revealed a hypoechoic, nonhomogeneous solid mass (21/17 $\mathrm{mm}$ ) with axillary lymphadenopathy. Computed tomography (CT) showed a well-rounded formation with a maximum diameter of $21 \mathrm{~mm}$ and two left axillary lymph nodes (16 and $14 \mathrm{~mm}$ ), which increased their density of the contrast series to a non-high degree (Figure 1). Because of the obvious attachment of the tumor to the underlying chest wall on US 
and $\mathrm{CT}$, we requested a Magnetic Resonance Imaging (MRI) to specify the infiltration. MRI on the FSE-XL/90 technique visualized a very well-distorted solid tumor lying on the chest wall. On the T1-contrast lesion series, the lesion raised its signal in the early series as the signal grew even further in the late series. None of them showed signs of involvement of the tumor to the underlying breast wall (Figure 2A and 2B). A fine-needle aspiration cytology (FNAC) was performed showing no evidence of cancer cells, but a slight suspicion of a granular cell tumor. Wide local excision of the lesion was done. The frozen section procedure confirmed "schwannoma of the breast" with signs of forming a pseudocapsule caused by the compression. Cut section of the $20 \mathrm{~mm}$ in diameter tumor showed well rounded, uniform, solid, white-yellowish and homogeneous mass that was slightly attached to the fascia of the great pectoral muscle (Figure 3). The surrounding breast parenchyma was found with fibrocystic alterations. No peripheral nerve was identified. Due to the precise intraoperative diagnosis and benign nature of the tumor we didn't perform an axillary lymph node biopsy. Microscopically the tumor was composed of sheets, nests, clusters and cords of rounded and polygonal cells. They were with an eosinophilic granular cytoplasm and round to oval, centrally located nuclei with an open chromatin pattern (PAS positive) (Figure 4A and 4B). The final histologic evaluation confirmed the diagnose - benign GCT $(20 \times 18 \mathrm{~mm})$ of the breast with margin widths $-15 \mathrm{~mm}$ distance from the breast tissue and $5 \mathrm{~mm}$ from the pectoral fascia. Immunohistochemical analysis revealed strong expression of S-100 protein, which supported the idea of neural origin (S-100 is also found in Schwann cells) (Figure 5). At the one year postoperative follow up there was no evidence of a recurrent lesion. The patient was advised to continue routine follow up.

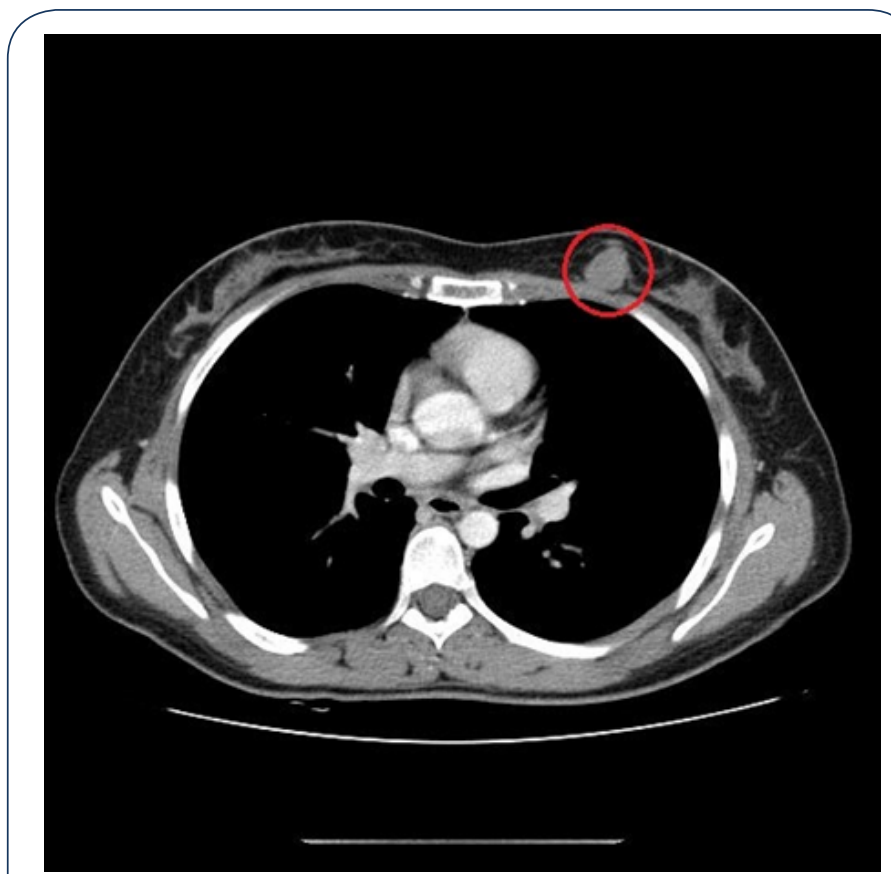

Figure 1 CT-contrast series showing attached to the chest wal well-rounded tumor (in the red circle). CT=computed tomography.
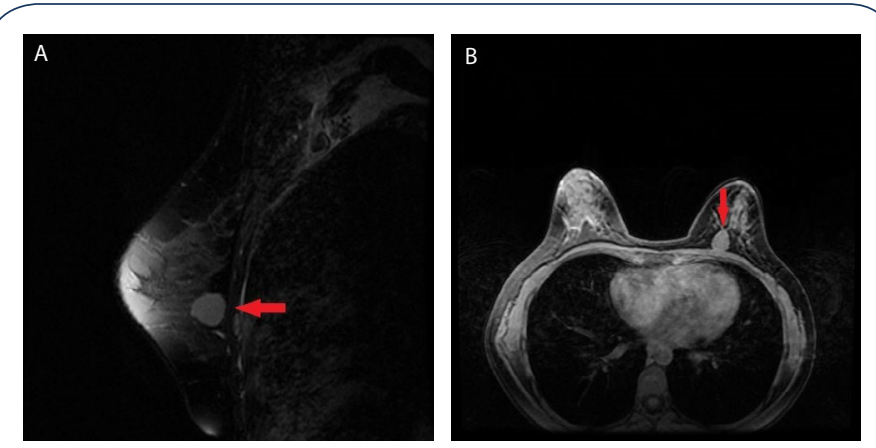

Figure 2 A) MRI - FSE-XL/90 contrast series showing the tumor (red arrow) and B) underlying chest wall with no evidence of invasion. $\mathrm{MRI}=$ Magnetic Resonance Imaging.

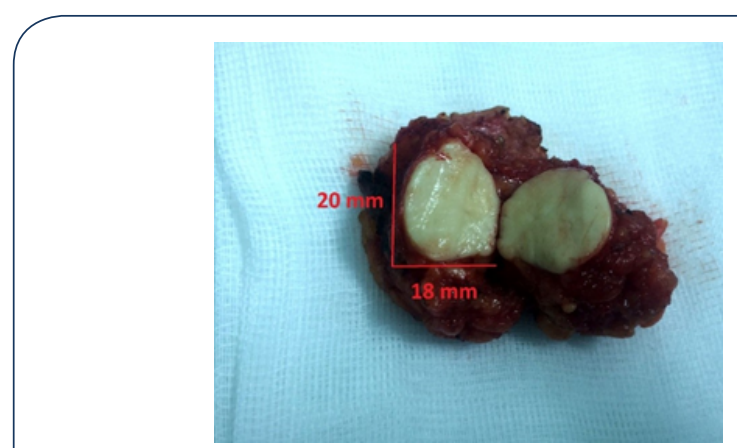

Figure 3 Macroscopic appearance of the benign granular-cell tumor in left breast.

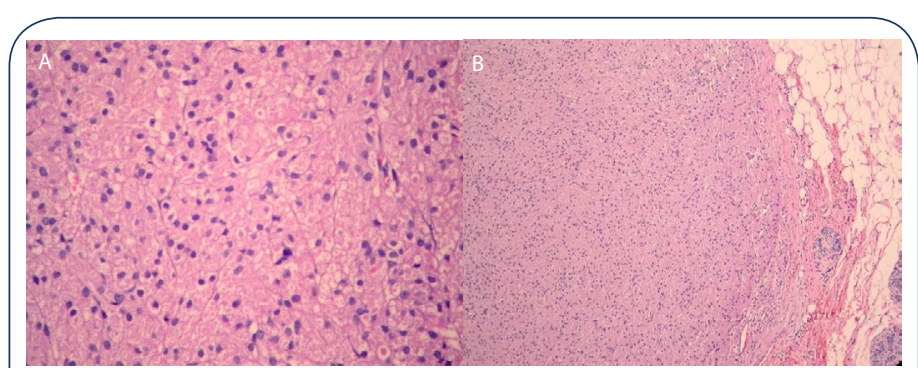

Figure 4 A, B) Microscopic view of the tumor (H\&E stain, $x 40$ ).

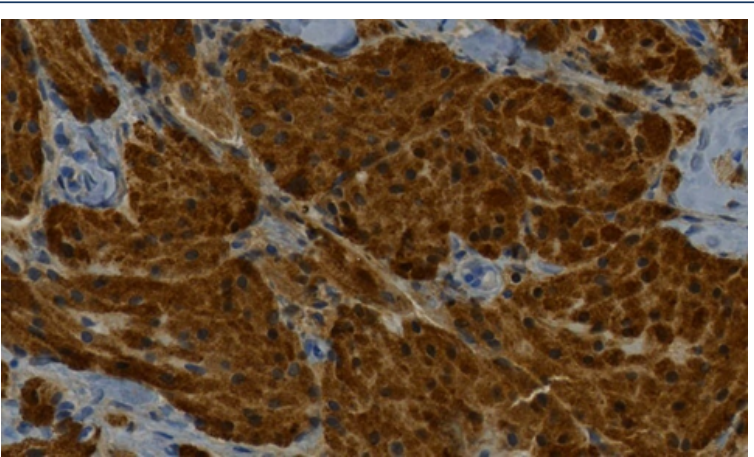

Figure 5 Immunohistochemically positivity for S-100 protein.

\section{Discussion}

Granular cell tumors (GCTs) are rare soft-tissue neoplasms probably derived from Schwann cells [6]. Most granular cell 
tumors are benign, although some may be locally aggressive. They are also known as Abrikossoff's tumors, Granular cell myoblastomas, Granular cell nerve sheath tumors and Granular cell schwannomas. Multiple granular cell tumors may be seen in the context of LEOPARD syndrome, due to a mutation in the PTPN11 gene [7]. Of all cases $40 \%$ arise in the tongue. In around $5-6 \%$ of cases GCT is observed in the breast, where it can be clinically and radiologically confused with a malignant breast tumor [8]. The granular component in these neoplasms is due to the accumulation of secondary lysosomes in the cytoplasm. This change is rather nonspecific and can be observed in many non-neural tumors, including those arising from smooth muscle, connective tissue, neuroglia, endothelial, and epithelial cells [9]. Exact data for the frequency are unavailable. Most of the literature on granular cell tumors consists of reports of single cases. Granular cell tumor (GCT) can affect any age, but usually the majority of cases are seen in the age group between 30 and 50, more common in females than males (3:1). The African American population shows a higher risk of developing this disease than the Caucasian one. There are reports showing presentation of the lesion from birth (congenital tumors), but without an association to any known congenital syndrome. GCT usually presents as a solitary non-tender nodule but not uncommonly is multifocal as a manifestation of multicentric disease. The tumor is often found in the upper inner quadrant unlike breast cancer, which is usually found in the upper outer quadrant [10-12]. Ultrasonography, mammography and MRI are widely employed and the most useful imaging techniques when investigating a breast mass. However, in GCT the radiological findings are often indistinguishable from breast cancer. GCT is usually benign but less than $2 \%$ of them show the tendency to become a malignant version, associated with a poor prognosis [3]. Histological findings that suggest a malignant disposition are a more rapid growth, larger size (more than $5 \mathrm{~cm}$ ), cellular and nuclear pleomorhism, high mitotic index, vascular invasion, cell spindling, prominent nucleoli and the presence of necrosis. Occuring in the breast, granular cell tumor poses a challenge in the differential diagnose, because it can easily mimic other frequent pathologies such as breast carcinoma, giant fibroadenoma or a phyllodes tumor [4,13]. Microscopic features of benign granular cell tumors are remarkably uniform,

\section{References}

1 Abrikossoff A (1926) Ueber Myome ausgehened von der quergestreiften willkuerlichen Muskulatur. Virchows Arch A Pathol Anat 260: 215-233.

2 Pushpa G, Karve PP, Subashini K, Narasimhan MN, Ahmad PB, et al. (2013) Abrikossoff's Tumor: An Unusual Presentation. Indian J Dermatol 58: 407.

3 Franzblau MJ, Manwaring M, Plumhof C, Listrom MB, Burgdorf WH, et al. (1989) Metastatic breast carcinoma mimicking granular cell tumor. J Cutan Pathol 16: 218-222.

4 Chung EM, Cube R, Hall GJ, González C, Stocker JT, et al. (2009) From the Archives of the AFIP: breast masses in children and adolescentsradiologic-pathologic correlation. Radio-Graphics 2009 29: 907-931.

5 Elkhateb S, Azzouzi-Idrissi M, Nicaise M, Gielen F, Masters-Watkins regardless of the site. Granular cell tumors are sometimes located near a nerve twig, usually within the perineurium and are variably circumscribed at the periphery [9]. Granular cell tumors have an uncertain histogenesis. Many immunohistochemical and ultrastructural studies suggest a Schwann cell origin [14]. The tumor cells stain positive for S-100 protein, neuron-specific enolase, and NK1-C3 in almost all cases. Positivity with stains for myelin-associated P0 and P2 proteins, myelin basic protein, and Leu-7 is less consistent. The tumor cells are non-immunoreactive for epithelial, muscle, endothelial, and glial cell markers. This is useful for differentiating a granular cell tumor from other diagnostic possibilities. Surgery is the mainstay of treatment for GCT. Resection with adequate margins is necessary because the tumor has no capsule and is proliferatively invasive [15]. The main complication of benign lesions is recurrence. In benign lesions, recurrence rates are $2-8 \%$, even when the resection margins are deemed free of tumor infiltration; they are around $20 \%$ when the margins are tumor-positive.

We've encountered the following diagnostic difficulties in our case: 1 . A young female, presented with a breast formation 5 months after giving birth. 2. The radiolocigal imaging (US and CT) showed infiltration to the chest wall and enlarged lymph nodes $(16 \mathrm{~mm})$ in the left axilla. 3. The patient refused routine tru-cut biopsy. 4 . The result from the FNAC was relatively insuffitient. All of the above troubled the preoperative differentiation of the tumor's nature - benign or malign. Our diagnostic and therapeutic approach was performed in conformity with the present treatment of Abrikossoff's tumor. At the one year postoperative follow up examination there was no evidence of residual or recurrent lesion. Surgery is the eestablished choice of treatment for Abrikossoff's tumor of the breast. In conclusion, granular cell tumor is one of the rarest tumors of the breast. Correct recognition of granular cell tumor is crucial for an adequate therapeutical approach and avoidance of any unnecessary procedures. Preoperative diagnosis with core biopsy can be useful for making the right surgical decision - wide local excision, rather than mastectomy [4]. Further studies are required for better future management and proper diagnosis of this rare cases.

$\mathrm{L}$, et al. (2008) Abrikossoff's rhabdomyoma presenting as a primary breast tumor: a case report. Gynecol Surg (2008) 5: 161-164.

6 Rejas RA, Campos MS, Cortes AR, Pinto DD, de Sousa SC (2011) The neural histogenetic origin of the oral granular cell tumor: an immunohistochemical evidence. Med Oral Patol Oral Cir Bucal 16: e6-e10.

7 Schrader KA, Nelson TN, De Luca A, Huntsman DG, McGillivray BC (2009) Multiple granular cell tumors are an associated feature of LEOPARD syndrome caused by mutation in PTPN11. Clin Genet 75: 185-189.

8 Adeniran A, Al-Ahmadie $\mathrm{H}$, Mahoney MC, Robinson-Smith TM (2004), Granular Cell Tumor of the Breast: A Series of 17 Cases and Review of the Literature. Breast J 10: 528-531.

9 Osipov V, Shidham V, Rao N, Pandit A (2016) Granular Cell Tumors. http://emedicine.medscape.com/article/282430-overview 
10 Patel A, Lefemine V, Yousuf SM, Abou-Samra W (2008) Granular cell tumor of pectoral muscle mimicking breast cancer. Cases J 1: 142.

11 Brown AC, Audisio RA, Regitnig P (2011) Granular cell tumour of the breast. Surg Oncol 20: 97-105.

12 Rexeena B, Paul A, Nitish RA, Kurian C, Anila RK, et al. (2015) Granular Cell Tumor of Breast: a Case Report and Review of Literature. Indian J Surg Oncol 6: 446-448.
13 Ilvan Ş, Üstündag N, Calay Z, Bükey Y (2005) Benign granular-cell tumour of the breast. Can J Surg 48: 155-156.

14 Bellezza G, Colella R, Sidoni A, Del Sordo R, Ferri I, et al. (2008) Immunohistochemical expression of Galectin-3 and HBME-1 in granular cell tumors: a new finding. Histol Histopathol 23: 1127-1130.

15 Aoyama K, Kamio T, Hirano A, Seshimo A, Kameoka S (2012) Granular cell tumors: a report of six cases. World J Surg Oncol 10: 204. 